\title{
Dramatic decline of the Vulnerable Reeves's pheasant Syrmaticus reevesii, endemic to central China
}

\author{
Chunfa Zhou, Jiliang Xu and Zhengwang Zhang
}

\begin{abstract}
The current status and distribution of the Vulnerable Reeves's pheasant Syrmaticus reevesii, endemic to central China, is poorly known. To obtain updated information on its status we selected 89 candidate sites in six provinces and one municipality in central China and conducted interviews and field surveys from April 2011 to April 2012. Interviews demonstrated the pheasant has disappeared from $46 \%$ of the surveyed sites. Our results also revealed a population decline at 46 sites, including protected areas, although population densities in protected areas were higher than those in non-protected areas. Eightythree, 26 and $20 \%$ of the surveyed sites had evidence of poaching, habitat loss and use of poison, respectively, which were the three major threats to this species. To ensure the long-term survival of Reeves's pheasant in China, protection and management need to be enforced in both protected and non-protected areas. We recommend that this species should be upgraded to a national first-level protected species in China and recategorized as Endangered on the IUCN Red List.
\end{abstract}

Keywords China, distribution, population status, Reeves's pheasant, Syrmaticus reevesii, threats

This paper contains supplementary material that can be found online at http://journals.cambridge.org

\section{Introduction}

$\mathrm{R}$ eeves's pheasant Syrmaticus reevesii, endemic to central R China, is categorized as Vulnerable on the IUCN Red List (IUCN, 2012) and as a national second-level protected species (State Council, 1988). It was once widely distributed and relatively common (Cheng et al., 1978). However, because of illegal hunting, habitat loss and fragmentation (Xu et al., 1991, 1995; MacKinnon et al., 1996; Zheng \& Wang, 1998), some populations have been extirpated and the species' range has become divided into eastern and western

Chunfa Zhou and Zhengwang Zhang (Corresponding author) Ministry of Education Key Laboratory for Biodiversity Science and Ecological Engineering, College of Life Sciences, Beijing Normal University, Beijing 100875, China E-mail zzw@bnu.edu.cn

JiLIANG Xu College of Nature Conservation, Beijing Forestry University, Beijing 100083, China

Received 27 February 2013. Revision requested 29 April 2013.

Accepted 12 June 2013. First published online 11 August 2014. regions (Zheng \& Wang, 1998; Collar et al., 2001). Reeves's pheasant is sensitive to expansion of development and there is no space for the species to shift its range in central China, especially with the high degree of habitat fragmentation in this area (Zheng \& Wang, 1998). Previous surveys (Xu et al., 1996; Ma et al., 2009) have indicated declines in the distribution and population density of Reeves's pheasant but these surveys did not cover the entire range of the species or lacked accurate data.

In the study reported here we conducted a large-scale and intensive survey of Reeves's pheasant from April 2011 to April 2012. We aimed to: (1) ascertain the current distribution and population status of Reeves's pheasant in China, (2) identify the challenges for its conservation, and (3) provide recommendations for appropriate conservation measures.

\section{Study area}

The survey covered the entire post-1980 range in which Reeves's pheasant was known to occur in central China (Anhui, Guizhou, Henan, Hubei, Hunan and Shaanxi provinces and Chongqing municipality; Fig. 1; Zheng \& Wang, 1998). This region is normally subject to the south-east subtropical monsoon, resulting in abundant precipitation and a moderate mean air temperature (Zhao et al., 2005). The natural vegetation of the region is evergreen broadleaf forest, deciduous broadleaf forest, or mixed conifer and broadleaf forest (Cheng et al., 1978; Wu et al., 1991, 1994; Xu et al., 1991). In addition to Reeves's pheasant, sympatric pheasants in this region include the ring-necked Phasianus colchicus, golden Chrysolophus pictus and koklass Pucrasia macrolopha pheasants, Temminck's tragopan Tragopan temminckii and five other species of Galliformes (Zheng, 2011).

\section{Methods}

We collected data on the historical distribution of Reeves's pheasant (Cheng et al., 1978; Xu et al., 1991; Zheng \& Wang, 1998; Collar et al., 2001) and on the current distribution, using interviews and field surveys. Personnel of provincial forestry departments responsible for wildlife conservation and management provided a general outline of the distribution of the species in each of the seven provinces/ municipality. We then consulted staff of relevant county 


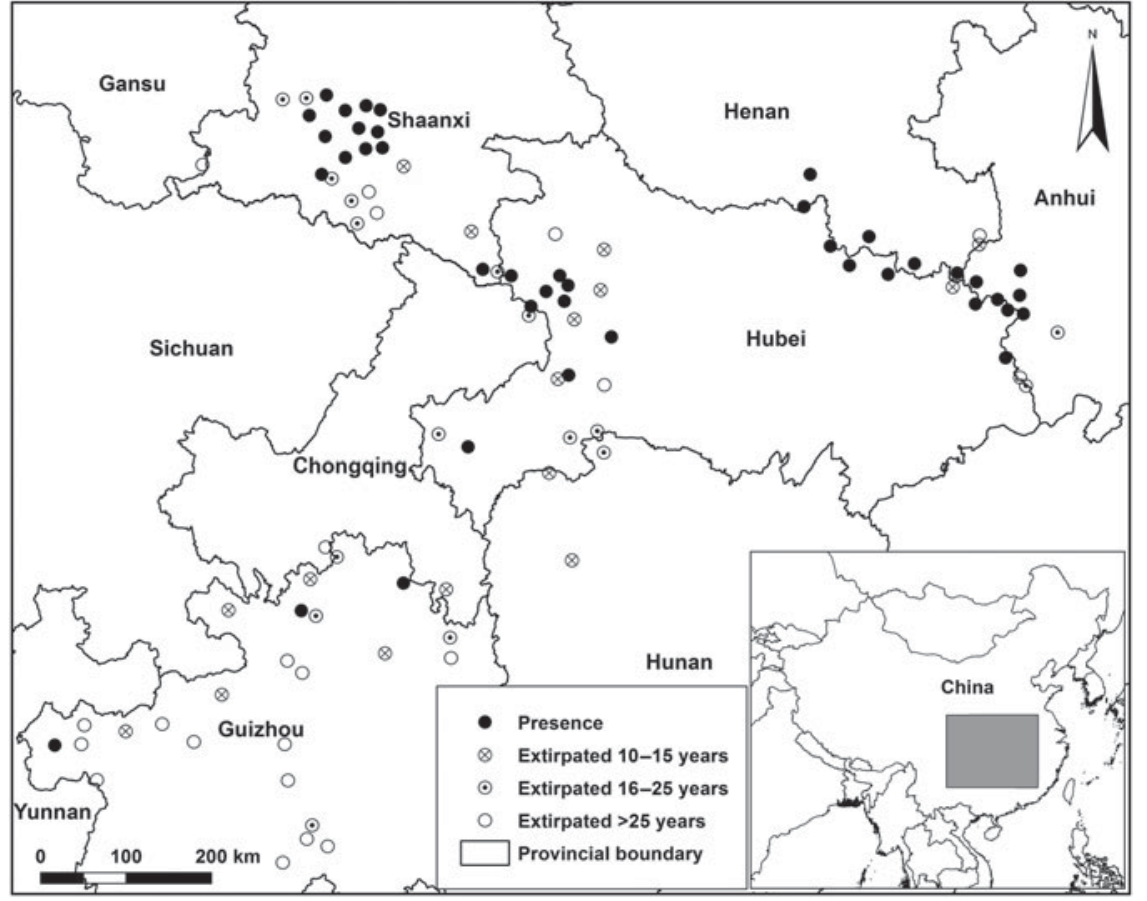

FIG. 1 The locations of sites surveyed for Reeves's pheasant Syrmaticus reevesii, indicating signs of presence and where the species appears to have been extirpated (some symbols represent more than one site). The rectangle on the inset indicates the location of the main map in China. forestry bureaus to obtain more detailed information on the species, obtaining such information for 78 counties $(71 \%$ of the 110 counties in which the species was known post-1980; Zheng \& Wang, 1998; Collar et al., 2001). In 60 of these counties we identified 78 candidate sites for further enquiries, and disregarded seven counties for which there was convincing evidence the species was extirpated. The 78 sites represented the best habitat for the survival of the pheasant in these counties; the distance between sites was at least $20 \mathrm{~km}$, reducing spatial autocorrelation (Dormann et al., 2007). From interviews with four local researchers familiar with Reeves's pheasant we obtained information on 11 more sites (Supplementary Table S1). Finally, we interviewed local residents to gather preliminary information on the status of and possible threats to Reeves's pheasant. When conducting interviews with village heads, elders and hunters, we verified the ability of the interviewees to identify Reeves's pheasant by showing them photographs of males of Reeves's, ring-necked, golden and koklass pheasants and Temminck's tragopan. In determining which sites to survey we only included information from interviewees who identified Reeves's pheasant correctly. Where there was no evidence of Reeves's pheasant for $>10$ years and no habitat suitable for the species we considered it to be locally extirpated (Harrison, 1991). During the surveys additional informal interviews were conducted to reaffirm findings.

We identified 43 sites for field surveys, for which we used the protocols employed by previous studies in the same area (Zhang, 2004; Liu, 2006). Line transect sampling was used to estimate the density of Reeves's pheasant. Transects of 850-3,600 m length across altitudes of 160-2,150 m were distributed randomly within survey sites and located using a global positioning system. We surveyed a fixed width of $50 \mathrm{~m}$ each side of the transects and within this assessed abundance by sightings, sound of wing-whirring displays and occurrence of moulted feathers. If two moulted feathers were found at least $300 \mathrm{~m}$ apart, we considered them as two independent individuals, given the home range size of Reeves's pheasant (Xu et al., 2009). Any evidence of poaching or illegal hunting (e.g. poachers, electric power lines set above the ground to kill passing wildlife, or traps encountered), and habitat loss or habitat fragmentation, was also recorded along the transects.

We calculated population density as the number of pheasants seen along a transect divided by the area of the transect (length x $100 \mathrm{~m}$; Bibby, 2000), and used MannWhitney $U$ tests to compare densities between protected and non-protected areas. We used paired sample $t$-tests to test the difference in population density between 2011-2012 and 2003-2005 (Zhang, 2004; Liu, 2006), as the values met the assumptions of a normal distribution. We classified the threats (indicated during interviews or observed along the transects) in each site and then ranked the main threats based on the percentage of survey sites with the corresponding threat. We used an $\alpha$ level of $\mathrm{P}<0.05$ for all statistical tests, which were performed with STATISTICA v. 10.0 (StatSoft, Tulsa, USA).

\section{Results}

To obtain general information about the status of Reeves's pheasant we interviewed 20 personnel of provincial and 
TABLE 1 Number of candidate sites (of 89 surveyed) where Reeves's pheasant Syrmaticus reevesii has declined, disappeared, or is stable, and the main threats or causes of extinction in the six provinces and one municipality in the post-1980 range of the species in central China.

\begin{tabular}{|c|c|c|c|c|c|c|}
\hline \multirow[b]{2}{*}{$\begin{array}{l}\text { Province/ } \\
\text { municipality }\end{array}$} & \multicolumn{5}{|c|}{ Number of sites } & \multirow[b]{2}{*}{ Main threats/cause of extirpation ${ }^{\star}$} \\
\hline & Declined & $\begin{array}{l}\text { Absent for } \\
10-15 \text { years }\end{array}$ & $\begin{array}{l}\text { Absent for } \\
16-25 \text { years }\end{array}$ & $\begin{array}{l}\text { Absent for } \\
>25 \text { years }\end{array}$ & Stable & \\
\hline Anhui & 7 & & 1 & & & Poaching, habitat loss \\
\hline Guizhou & 4 & 4 & 4 & 4 & & Poaching, poison, habitat loss \\
\hline Henan & 5 & 1 & & 1 & 1 & Poaching, habitat loss, inappropriate management \\
\hline Hubei & 15 & 4 & 3 & 3 & 1 & Poaching, habitat loss, poison \\
\hline Hunan & & & 3 & & & Inappropriate management, poaching \\
\hline Shaanxi & 14 & 3 & 4 & 2 & & Poaching, poison, habitat loss \\
\hline Chongqing & 1 & 2 & 1 & 1 & & Poaching, habitat loss, inappropriate management \\
\hline Total & 46 & 14 & 16 & 11 & 2 & \\
\hline
\end{tabular}

${ }^{*}$ Only the three main factors are listed; for full details of threats, see Supplementary Table S1.

TABLE 2 The number of sites and line transects and total length of transects surveyed in the provinces in which there was convincing evidence of the presence of Reeves's pheasant, with number of individual pheasants detected, population density, and number of sites with evidence of poaching (including the number of electric fences, hunters or traps found or observed).

\begin{tabular}{|c|c|c|c|c|c|c|c|c|c|}
\hline Province & $\begin{array}{l}\text { No. of } \\
\text { sites }\end{array}$ & $\begin{array}{l}\text { No. of } \\
\text { transects }\end{array}$ & $\begin{array}{l}\text { Transect } \\
\text { length }(\mathrm{km})\end{array}$ & $\begin{array}{l}\text { No. of } \\
\text { individuals } \\
\text { detected }\end{array}$ & $\begin{array}{l}\text { Population } \\
\text { density }\left(\mathrm{km}^{-2}\right)\end{array}$ & $\begin{array}{l}\text { No. of sites with } \\
\text { poaching } \\
\text { evidence }\end{array}$ & $\begin{array}{l}\text { No. of } \\
\text { electric } \\
\text { fences }\end{array}$ & $\begin{array}{l}\text { No. of } \\
\text { hunters }\end{array}$ & $\begin{array}{l}\text { No. of } \\
\text { traps }\end{array}$ \\
\hline Anhui & 5 & 24 & 33.35 & 14 & $0-10.04$ & 5 & 5 & 1 & 33 \\
\hline Guizhou & 3 & 14 & 17.04 & 27 & $0-32.77$ & 2 & & 1 & 2 \\
\hline Henan & 6 & 39 & 61.17 & 42 & $0-11.36$ & 6 & 16 & & 13 \\
\hline Hubei & 15 & 67 & 83.85 & 87 & $0-33.36$ & 12 & 4 & 11 & 77 \\
\hline Shaanxi & 14 & 65 & 54.89 & 27 & $0-15.75$ & 11 & 1 & 7 & 47 \\
\hline Total & 43 & 209 & 250.3 & 197 & $0-33.36$ & 36 & 26 & 20 & 172 \\
\hline
\end{tabular}

county forestry sectors, 50 personnel of nature reserves and forest parks, 35 heads of local village committees, 184 elders, and 44 hunters. The pheasant has disappeared from $46 \%$ $(\mathrm{n}=41)$ of the sites investigated, especially in the south-west of the western regions (Fig. 1, Table 1), and has been extirpated for 10-15, 16-25 and $>25$ years at 14,16 and 11 sites, respectively. Only half $(n=39)$ of the counties we surveyed had evidence of presence of the species. The interviews also indicated that Reeves's pheasant has declined at 46 sites (Supplementary Table S1).

We walked a total of $250.3 \mathrm{~km}$ along 209 line transects and recorded 197 individual Reeves's pheasant at 43 sites in 32 counties (Table 2). The pheasant occurred in $60 \%$ of protected areas $(n=40)$ and $50 \%$ of non-protected areas $(\mathrm{n}=38)$ surveyed. Population densities in protected areas were higher than those in non-protected areas (Mann-Whitney $U$ Test, $Z=-2.092, \mathrm{df}=42, \mathrm{P}<0.05$ ), and significantly lower in eight protected areas compared to 2003-2005 (paired sample $t$-test, $t=-4.66, \mathrm{df}=7, \mathrm{P}<0.01$; Fig. 2).

Approximately 83,26 and $20 \%$ of the surveyed sites had direct evidence of poaching, habitat loss and use of poison, respectively, but the extent of threats varied between sites (Supplementary Table S1). Along our line transects

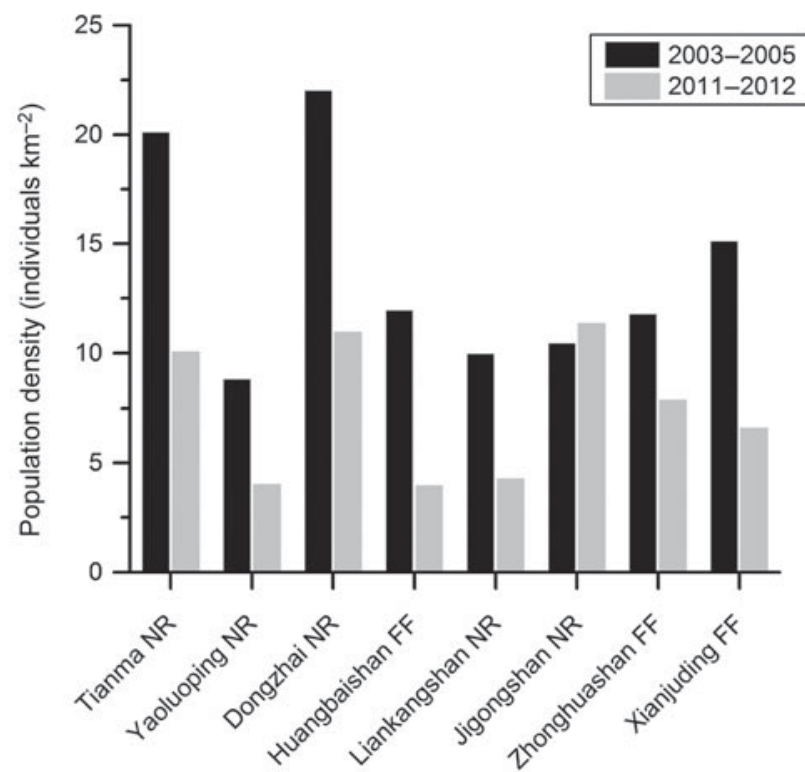

FIG. 2 The population density of Reeves's pheasant in 2003-2005 (Zhang, 2004; Liu, 2006) and in 2011-2012 (this survey). NR, Nature Reserve; FF, Forest Farm. 
we found 172 snares, 26 electric fences and 20 poachers at $36(83 \%)$ sites (Table 2 ).

\section{Discussion}

\section{Distribution and population status}

Reeves's pheasant was widely distributed in central China in the relatively recent past (Cheng et al., 1978). However, we did not find any evidence of its presence in almost half of the candidate sites. In particular, we only confirmed the presence of this pheasant in four, isolated, sites of the 16 sites in Guizhou province where Reeves's pheasant had been recorded previously (Wu \& Xu, 1987; Wu et al., 1991). Our findings can be interpreted conservatively as demonstrating a decline in the population of this species. Given the continued human population increase and considering the social and economic development plans for these areas (Lu \& Deng, 2011), it is reasonable to assume that the range of this pheasant could become further restricted.

Although it is more difficult to clarify the status of a species than to determine its distribution (Brickle et al., 2008), our results indicated declines of Reeves's pheasant at most surveyed sites. The population in the Tuoda Nature Reserve was c. 240 during 1991-1994 (Yu et al., 2011) but we recorded only one Reeves's pheasant in 2012. Declines have also occurred in some protected areas.

\section{Threats}

Poaching is a key threat to wildlife in developing countries (McGowan, 2002). It not only affects the survival of pheasant species but also reduces other wildlife populations and biodiversity (Li et al., 2007). The long tail feathers of the male Reeves's pheasant are widely used for the decoration of Chinese opera costumes (Cheng et al., 1978) and consequently a great number of Reeves's pheasants are hunted (Supplementary Table $\mathrm{S}_{2}$ ). The harvest of tail feathers from males was still occurring in Henan, Hubei and Anhui provinces during our survey (Supplementary Table S2). People in rural areas were not familiar with national wildlife conservation policies and, for example, did not know of the importance of Reeves's pheasant. Although the government has carried out public outreach programmes most of these have been in small towns, and it has been difficult to disseminate appropriate messages to rural and remote areas (Zhang et al., 2008). Overlap and conflicts in wildlife conservation and management between government departments (e.g. Xu et al., 2012) have also exacerbated these problems.

Most Galliformes are sensitive to habitat destruction, and their populations decrease following loss of suitable habitat (Wang et al., 2008). Reeves's pheasant prefers habitats with large trees and extensive canopy cover and sparse undergrowth (Xu et al., 1991, 2002, 2007; Wu et al., 1994). However, the increasing human population and booming economy in China since 1980 has led to increased deforestation ( $\mathrm{Li}, 2004)$. The Chinese government has initiated forest conservation programmes, most notably after the Yangtze River flood in 1998, but forest degradation caused by inappropriate exploitation remains a serious threat (Liao, 1999; Li, 2004). For example, the population density of Reeves's pheasant at Xianjuding forest farm, a site we surveyed, declined from 15.10 to 6.59 per $\mathrm{km}^{2}$ when the mature forest was logged for commercial purposes (Zhang, 2004). Subsequent habitat fragmentation is a further threat (Fahrig, 2002). It reduces the area of suitable habitat and affects the movement of the pheasant, and higher predation at habitat edges may lead to further population reduction (Chalfoun et al., 2002; Fahrig, 2003).

Farmers in China deliberately poison Galliformes to prevent them from eating crop seeds (Zhang et al., 2003). Our survey indicated that poison was used in particular in the dry western region, which is only suitable for planting corn and beans. Planting of these crops was coincident with a shortage of food for pheasants before the breeding season (Johnsgard, 1999).

\section{Management implications}

Because of the Vulnerable status and rapidly declining population of Reeves's pheasant, the Chinese government and relevant international organizations (IUCN, Zheng \& Wang, 1998; World Pheasant Association, McGowan et al., 2009) have taken measures to protect the species. However, the conservation framework was based on population and distribution data from the 1980 s and, as a result, some conservation measures may no longer be appropriate.

The government is upgrading wildlife conservation policies; e.g. National Biodiversity Strategies and Action Plans in China 2011-2030 (Ministry of Environmental Protection, 2010) and The 12th 5-Year Plan on Wildlife Conservation and Nature Reserve Management in China (State Forestry Administration, 2012). Changes include revising threatened species lists, public outreach, amending the Law of Wildlife Conservation, and drafting legislation on nature reserves. To provide the foundation for future conservation of Reeves's pheasant we propose, based on our findings, that the species should be upgraded to a first-grade nationally protected species. We also recommend that its status on the IUCN Red List should be changed to Endangered, based on criterion Azacd (i.e. population reduction of $\geq 50 \%$ over the last 10 years, with direct observation (a), decline of Extent of Occurrence (c), and overexploitation (d) (IUCN, 2001).

As Reeves's pheasant is important to people, its effective conservation needs to include a sensitive combination of 
community development, education, habitat management and law enforcement (He et al., 2004; Liang et al., 2006; Li et al., 2007). To improve public awareness, relevant community outreach needs to be developed and implemented in a manner that is accessible to rural populations. Poaching and poisoning should be banned and economic compensation should be provided to farmers who suffer when their crops are eaten by this pheasant (State Forestry Administration, 2012).

Establishment of protected areas, especially nature reserves, has been fundamental to wildlife conservation in China (Xu et al., 2012). However, management policies are often incompatible with the objectives of nature reserves, including inappropriate regulations (Xu \& Melick, 2006), limited capacity, improper reserve management techniques, and inappropriate budget allocations (Quan et al., 2011). Improving the management effectiveness of nature reserves is therefore a priority for biodiversity conservation (Ministry of Environmental Protection, 2010; State Forestry Administration, 2012). Promoting management of nature reserves will be beneficial to biodiversity conservation in China, and improving management of the reserves for Reeves's pheasant will protect both this pheasant and its habitat.

\section{Acknowledgements}

This research was supported by the Forestry Commonwealth Programmes (No. 200904003), the National Science and Technology Ministry (2008BAC39B05), the National Natural Science Foundation (No. 31172115), a grant from the State Forestry Administration and the 985 Project of Beijing Normal University. We thank the Forestry Departments of Anhui, Hubei, Guizhou and Shaanxi Provinces for permission and support for the surveys, the local residents, authorities and nature reserve managers for providing us with data and assistance, and Yang Liu and anonymous reviewers for valuable comments and suggestions.

\section{References}

Biв в y, C.J. (2000) Bird Census Techniques. Academic Press, San Diego, USA.

Brickle, N.W., Duckworth, J.W., Tordoff, A.W., Poole, C.M., Timmins, R. \& McGowan, P.J.K. (2008) The status and conservation of Galliformes in Cambodia, Laos and Vietnam. Biodiversity and Conservation, 17, 1393-1427.

Chalfoun, A.D., Thompson, F.R. \& Ratnaswamy, M.J. (2002) Nest predators and fragmentation: a review and meta-analysis. Conservation Biology, 16, 306-318.

Cheng, T.H., TAn, Y.K., Lu, T.C., TAnG, C.Z., BAo, G.X. \& Li, F.L. (1978) Fauna Sinica, Aves Vol. 4: Galliformes. Science Press, Beijing, China.

Collar, N., Andreev, A., Chan, S., Crosby, M., Subramanya, S. \& Tobias, J. (2001) Threatened Birds of Asia: The BirdLife
International Red Data Book. BirdLife International,

Cambridge, UK.

Dormann, C.F., McPherson, J.M., Araujo, M.B., Bivand, R., Bolliger, J., CARL, G. et al. (2007) Methods to account for spatial autocorrelation in the analysis of species distributional data: a review. Ecography, 30, 609-628.

FAHRIG, L. (2002) Effect of habitat fragmentation on the extinction threshold: a synthesis. Ecological Applications, 12, 346-353.

FAHRIG, L. (2003) Effects of habitat fragmentation on biodiversity. Annual Review of Ecology, Evolution, and Systematics, 34, 487-515.

HARRISON, S. (1991) Local extinction in a metapopulation context: an empirical evaluation. Biological Journal of the Linnean Society, 42, $73-88$.

He, L., García-Perea, R., Li, M. \& Wei, F. (2004) Distribution and conservation status of the endemic Chinese mountain cat Felis bieti. Oryx, 38, 55-61.

IUCN (2001) IUCN Red List Categories and Criteria (version 3.1). IUCN, Gland, Switzerland, and Cambridge, UK.

IUCN (2012) IUCN Red List of Threatened Species v. 2012.1. Http:// www.iucnredlist.org [accessed 29 July 2012].

Johnsgard, P.A. (1999) The Pheasants of the World: Biology and Natural History. Smithsonian Institution Press, Washington, DC, USA.

LI, W.H. (2004) Degradation and restoration of forest ecosystems in China. Forest Ecology and Management, 201, 33-41.

Li, Y., Huang, C., Ding, P., Tang, Z. \& Wood, C. (2007) Dramatic decline of François' langur Trachypithecus francoisi in Guangxi Province, China. Oryx, 41, 38-43.

LiAnG, W., CAI, Y. \& YANG, C.C. (2006) Extreme levels of hunting of birds in a remote village of Hainan Island, China. Bird Conservation International, 1, 1-8.

Lia , Y.H. (1999) Rebuilt the Green Great Wall: a report from the stop-logging areas in West Sichuan. Decision and Information, $173,4-5$.

Liu, Y. (2006) The home range and dispersal of female Reeves's pheasant (Syrmaticus reevesii) in Henan. MSc thesis. Beijing Normal University, Beijing, China.

Lu, Z. \& Deng, X. (2011) China's Western Development Strategy: Policies, Effects and Prospects. MPRA Paper 35201. University Library of Munich, Germany.

Ma, F., Zhang, J.L., WAnG, W., Liu, G.Q., Chen, J.W., Zhuo, R.S. et al. (2009) China Key Terrestrial Wildlife Resources Survey. pp. 191193. Chinese Forestry Press, Beijing, China.

MacKinnon, J., Meng, S., Carey, C., Zhu, X. \& Melville, D. (1996) A Biodiversity Review of China. WWF International China Programme, Hong Kong, China.

McGowan, P. (2002) The conservation implications of the hunting of Galliformes and the collection of their eggs. In Links Between Biodiversity Conservation, Livelihood and Food Security: The Sustainable Use of Wild Species for Meat (eds S.A. Mainka \& M. Trivedi), pp. 85-93. IUCN, Gland, Switzerland, and Cambridge, UK.

McGowan, P.J.K., ZhanG, Y.Y. \& ZhanG, Z.W. (2009) Galliformes-barometers of the state of applied ecology and wildlife conservation in China. Journal of Applied Ecology, 46, 524-526.

Ministry of Environmental Protection (2010) National Biodiversity Strategies and Action Plans in China (2011-2030). Http://www.gov.cn/gzdt/2010-02/24/content_1540249.htm [accessed 1 May 2013].

Quan, J., OUYanG, Z.Y., Xu, W.H. \& Miao, H. (2011) Assessment of the effectiveness of nature reserve management in China. Biodiversity and Conservation, 20, 779-792. 
State Council (1988) The List of Wild Animals Under National Protection Issued by the State Council of the People's Republic of China on 10 December 1988. State Council, Beijing, China.

State Forestry Administration (2012) The 12th Five-Year Plan on Wildlife Conservation and Nature Reserve Management in China. Http://www.gov.cn/gzdt/2012-02/29/content_2079016.htm [accessed 1 May 2013].

Wang, W., Ren, G., He, Y. \& ZHU, J. (2008) Habitat degradation and conservation status assessment of Gallinaceous birds in the Trans-Himalayas, China. Journal of Wildlife Management, 72, 1335-1341.

W U, Z.K., Li, Z.M. \& WANG, J.H. (1994) Progress in research on Reeves's pheasant in China. Annual Review of the World Pheasant Association, 1993/1994, 39-43.

Wu, Z.K., LI, Z.M. \& XU, W.S. (1991) Distribution and population density of the Reeves's pheasant. Guizhou Science, 9, 215-219.

Wu, Z.K. \& XU, W.S. (1987) On the geographical distribution and abundance of white crowned long tailed pheasants in Guizhou Province. Zoological Research, 8, 13-19.

XU, J.C. \& MELICK, D.R. (2006) Rethinking the effectiveness of public protected areas in southwestern China. Conservation Biology, 21, $318-328$.

Xu, J.L., Zhang, X.H., Sun, Q.H., Zheng, G.M., Wang, Y. \& ZHANG, Z.W. (2009) Home range, daily movements and site fidelity of male Reeves's pheasants Syrmaticus reevesii in the Dabie Mountains, central China. Wildlife Biology, 15, 338-344.

XU, J.L., Zhang, X.H., Zhang, Z.W. \& Zheng, G.M. (2002) Brood habitat characteristics of Reeves's pheasant (Syrmaticus reevesii) in Dongzhai National Nature Reserve. Zoological Research, $23,471-476$.

Xu, J.L., Zhang, Z.W., LiU, W.J. \& McGowan, P.J.K. (2012) A review and assessment of nature reserve policy in China: advances, challenges and opportunities. Oryx, 46, 554-562.

Xu, J.L., Zhang, Z.W., Zheng, G.M., Zhang, X.H., Sun, Q.H. \& McGowan, P. (2007) Home range and habitat use of Reeves's pheasant Syrmaticus reevesii in the protected areas created from forest farms in the Dabie Mountains, central China. Bird Conservation International, 17, 319-330.

XU, W.S., WU, Z.K. \& LI, Z.M. (1991) Reeves's pheasant (Syrmaticus reevesii). In The Rare and Endangered Gamebirds in China (eds T.C.
Lu, R.S. Liu \& F.Q. He), pp. 328-338. Fujian Science and Technology Press, Fuzhou, China.

Xu, Y.G., Yin, Z.H., LeI, F.M., Ding, W.N., LiU, R.S. \& YU, Q. (1996) The status of Reeves's pheasant and suggestions for conservation. Acta Zoologica Sinica, 42, 155.

Xu, Y.G., Yin, Z.H., Zhang, K.Y., ZHAnG, X.F. \& GAO, Z.J. (1995) The status of Reeves's pheasant at Dongzhai of Henan province and suggestion for conservation. Sinozoologia, 12, 335-341.

Yu, Z.G., JiAnG, H., Li, F. \& Li, Z.M. (2011) Bird resource survey in Tuoda Nature Reserve and analysis on causes for disappearance of Reeves's pheasant. Guizhou Science, 29, 44-59.

ZHANG, L., HuA, N. \& SUN, S. (2008) Wildlife trade, consumption and conservation awareness in southwest China. Biodiversity and Conservation, 17, 1493-1516.

ZHANG, X.H. (2004) Breeding behavior and breeding habitat of Reeves's pheasant (Syrmaticus reevesii). PhD thesis. Beijing Normal University Beijing, China.

Zhang, Z.W., Ding, C.Q., Ding, P. \& Zheng, G.M. (2003) The current status and a conservation strategy for species of Galliformes in China. Biodiversity Science, 11, 414-421.

Zhao, C.M., Chen, W.L., Tinn, Z.Q. \& Xie, Z.Q. (2005) Altitudinal pattern of plant species diversity in Shennongjia Mountains, Central China. Journal of Integrative Plant Biology, 47, 1431-1449.

Zheng, G.M. (2011) A Checklist on the Classification and Distribution of the Birds of China. 2nd edition. Science Press, Beijing, China.

Zheng, G.M. \& Wang, Q.S. (1998) China Red Data Book of Endangered Animals (Aves). Science Press, Beijing, China.

\section{Biographical sketches}

Chunfa $\mathrm{ZHOU}$ is studying the habitat, distribution and status of Reeves's pheasant. Jiliang XU is a member of the IUCN Species Survival Commission Pheasant Specialist Group, with interests in research on threatened pheasant species, nature reserve design and management, and biodiversity conservation policy. ZHENGWANG ZH ANG is the Vice President of the China Ornithological Society and his research interests focus on the ecology of rare and threatened Galliformes, conservation biology and the spatial and temporal distribution patterns of waterbirds. 